\title{
Formation of pure $\mathrm{Cu}$ nanocrystals upon post-growth annealing of $\mathrm{Cu}-\mathrm{C}$ material obtained from focused electron beam induced deposition: comparison of different methods
}

\author{
Aleksandra Szkudlarek ${ }^{1,2}$, Alfredo Rodrigues Vaz ${ }^{1,3}$, Yucheng Zhang ${ }^{4}$, \\ Andrzej Rudkowski ${ }^{5}$, Czesław Kapusta ${ }^{5}$, Rolf Erni ${ }^{4}$, Stanislav Moshkalev ${ }^{3}$ and Ivo Utke ${ }^{* 1}$
}

\section{Full Research Paper}

\section{Address:}

${ }^{1}$ Empa, Swiss Federal Laboratories for Materials Science and

Technology, Laboratory for Mechanics of Materials and

Nanostructures, Feuerwerkerstrasse 39, 3602 Thun, Switzerland,

${ }^{2} \mathrm{AGH}$ University of Science and Technology, Academic Centre for

Materials and Nanotechnology, al. A. Mickiewicza 30, 30-059 Krakow,

Poland, ${ }^{3}$ Center for Semiconductor Components, State University of

Campinas, 13083-870, Campinas, SP, Brazil, ${ }^{4}$ Empa, Swiss Federal

Laboratories for Materials Science and Technology, Electron

Microscopy Center, Überlandstrasse 129, 8600 Dübendorf,

Switzerland and ${ }^{5} \mathrm{AGH}$ University of Science and Technology, Faculty

of Physics and Applied Computer Science, Department of Solid State

Physics, al. A. Mickiewicza 30, 30-059 Krakow, Poland

Email:

Ivo Utke - ivo.utke@empa.ch

* Corresponding author

Keywords:

$\mathrm{Cu}(\mathrm{hfac})_{2}$; Cu nanocrystals; focused electron beam induced

deposition (FEBID); post-growth annealing of $\mathrm{Cu}-\mathrm{C}$ material

\begin{abstract}
In this paper we study in detail the post-growth annealing of a copper-containing material deposited with focused electron beam induced deposition (FEBID). The organometallic precursor $\mathrm{Cu}(\mathrm{II})(\mathrm{hfac})_{2}$ was used for deposition and the results were compared to that of compared to earlier experiments with (hfac) $\mathrm{Cu}(\mathrm{I})(\mathrm{VTMS})$ and (hfac)Cu(I)(DMB). Transmission electron microscopy revealed the deposition of amorphous material from $\mathrm{Cu}(\mathrm{II})(\mathrm{hfac})_{2}$. In contrast, as-deposited material from (hfac)Cu(I)(VTMS) and $($ hfac $) \mathrm{Cu}(\mathrm{I})(\mathrm{DMB})$ was nano-composite with $\mathrm{Cu}$ nanocrystals dispersed in a carbonaceous matrix. After annealing at around 150-200 ${ }^{\circ} \mathrm{C}$ all deposits showed the formation of pure $\mathrm{Cu}$ nanocrystals at the outer surface of the initial deposit due to the migration of $\mathrm{Cu}$ atoms from the carbonaceous matrix containing the elements carbon, oxygen, and fluorine. Post-irradiation of deposits with $200 \mathrm{keV}$ electrons in a transmission electron microscope favored the formation of Cu nanocrystals within the carbonaceous matrix of freestanding rods and suppressed the formation on their surface. Electrical four-point measurements on FEBID lines from $\mathrm{Cu}(\mathrm{hfac})_{2}$ showed five orders of magnitude improvement in conductivity when being annealed conventionally and by laser-induced heating in the scanning electron microscope chamber.
\end{abstract}

\begin{abstract}
Beilstein J. Nanotechnol. 2015, 6, 1508-1517.
\end{abstract}
Received: 16 March 2015

Accepted: 24 June 2015

This article is part of the Thematic Series "Focused electron beam induced processing".

Guest Editor: M. Huth

(C) 2015 Szkudlarek et al; licensee Beilstein-Institut. License and terms: see end of document. 


\section{Introduction}

Focused electron beam induced deposition (FEBID) is a direct maskless nanolithography technique, based on the local dissociation of adsorbates upon the irradiation with electrons [1]. The molecules are delivered into the microscope chamber by a gas injection system (GIS) where they reversibly physisorb onto the substrate surface. Part of the energy from the primary electron beam or from the secondary electrons generated in the vicinity of the impinging primary beam is transferred to the adsorbates and breaks their chemical bonds. The non-volatile fragments stick to the substrate surface whereas the volatile fragments are removed from the chamber by the pumping system. By controlling the beam scanning three dimensional structures of a complex shape can be created in a single direct-write deposition step onto planar or non-planar surfaces [2].

Nanodevices with various functionalities have been deposited comprising gas sensors $[3,4]$, magnetic sensors [5,6] strain sensors [7], thermal sensors [8], photodetectors [9], and mode stabilizers for vertical surface emitting lasers [10]. Other deposits were used as ferromagnetic wires [11,12], superconducting wires [13], plasmonic structures [14], or as electrode nanocontacts $[15,16]$. The feasibility of obtaining 3D nanostructures with a high aspect ratio makes FEBID suitable for fabrication of high resolution probes to scanning magnetic force microscopy (MFM) [17-19].

\section{Purification methods of FEBID structures}

For FEBID direct-write nanostructures lateral resolution can be well-controlled by adjusting the beam and gas flow settings [20] as well as by optimizing scanning strategies [21]. However, the purity of FEBID materials obtained with organic precursors still remains an issue. Recently, post-growth purification methods using electron beam irradiation in combination with thermal annealing and co-injection of reactive gases/ions were developed. In the case of $\mathrm{Pt}-\mathrm{C}$ deposits, the catalytic properties of $\mathrm{Pt}$ nanoparticles facilitate the process of molecular oxygen dissociation, thereby increasing the efficiency of removing the carbonaceous matrix [22]. Pure Pt material was obtained with a post deposition treatment using $\mathrm{O}_{2}$ gas and a) laser pulsing [23] or b) low-temperature substrate annealing (up to $50^{\circ} \mathrm{C}$ ) [24]. The presence of $\mathrm{H}_{2} \mathrm{O}$ during electron irradiation performed at $\mathrm{rt}$ allowed for a total elimination of carbon from $\mathrm{Pt}-\mathrm{C}$ deposits without affecting the shape [25]. The combination of thermal heating to $300{ }^{\circ} \mathrm{C}$, injection of $\mathrm{H}_{2}$ gas and simultaneous electron irradiation led to pure Co deposits [26]. Microstructural changes were observed upon simple $5 \mathrm{keV}$ electron beam curing of FEBID structures. The $\mathrm{Pt}-\mathrm{C}$ deposits exhibited an increased conductivity by three to four orders of magnitude $[27,28]$. For $\mathrm{W}-\mathrm{C}$ deposits an improvement of one order of magnitude was found [29].
Conventional post-growth annealing of FEBID material in vacuum was summarized in a review by Botman et al. [30]: The thermal energy which is delivered to the sample can cause a desorption of carbonaceous fragments increasing the metal concentration from 15 atom $\%$ of $\mathrm{Au}$ (rt) to 24 atom $\%$ of $\mathrm{Au}$ (at $100{ }^{\circ} \mathrm{C}$ ). Increasing the substrate temperature during FEBID also favors the desorption of non-metallic dissociation by-products as it was observed by Mulders et al. [31] for various precursors: TEOS (tetraethylorthosilicate), $\mathrm{Co}(\mathrm{CO})_{3} \mathrm{NO}$, $\mathrm{Co}_{2}(\mathrm{CO})_{8}$, and $\mathrm{Me}_{2} \mathrm{Au}(\mathrm{acac})$ with the best purity enhancement for $\mathrm{W}(\mathrm{CO})_{6}$ (from 37 atom $\%$ at $25{ }^{\circ} \mathrm{C}$ to 59 atom $\%$ of $\mathrm{W}$ at $280^{\circ} \mathrm{C}$ ). However, the temperature rise during the deposition may not be favorable as it also decreases the residence time of adsorbates, significantly lowering the growth rate. Furthermore, the high temperature may also cause the diffusion of deposit atoms into or from the substrate.

A compromise approach is based on pulsed heating with an IR laser as a heat source which can generate abrupt temperature peaks in the microseconds range only (sufficient for desorption), allowing the substrate surface to equilibrate quickly and to replenish with new adsorbates before the next electronbeam scan frame. FEBID together with synchronized pulsed IR laser heating helped to increase the metal concentration of $\mathrm{Au}$, $\mathrm{W}, \mathrm{Pt}$ in FEBID deposits, however, did not fully remove the carbon. For deposits obtained from $\mathrm{Me}_{2} \mathrm{Au}(\mathrm{acac})$ the initial atomic ratio of $\mathrm{C}$ to $\mathrm{Au}$ decreased from 4 to 0.5 with the laser assistance [32]. For $\mathrm{W}(\mathrm{CO})_{6}$ FEBID the atomic ratio of $\mathrm{W}$ to $\mathrm{C}$ was improved from 1:4 to 2:1 [33]. For $\mathrm{MePtCpMe}_{3}$ FEBID the Pt concentration increased from about 15 atom \% to 35 atom \% [34]. Such an improvement was not observed when using a conventional heating stage during the deposition process with $\mathrm{MePtCpMe}_{3}$. The deposit obtained at $350{ }^{\circ} \mathrm{C}$ did not exhibit a different $\mathrm{Pt} / \mathrm{C}$ ratio than the deposit obtained at room temperature, where 15 atom \% Pt were measured [31].

\section{Copper purification}

The very high conductivity of copper makes the localized deposition of this metal very attractive for applications in nano-electronics. The organometallic hexafluoroacetylacetonate (hfac)based $\mathrm{Cu}(\mathrm{I})$ and $\mathrm{Cu}(\mathrm{II})$ precursors are widely used in chemical vapor deposition (CVD) methods due to their stability and high vapor pressure. They allow to obtain pure metal CVD films with the same resistivity as in a bulk material at deposition temperatures below $300{ }^{\circ} \mathrm{C}$ [35-37].

Recently, it was shown for condensed monolayers of $\mathrm{Cu}(\mathrm{hfac})_{2}$ (also $\mathrm{Pt}(\mathrm{hfac})_{2}$ and $\mathrm{Pd}(\mathrm{hfac})_{2}$ ) that electron-beam irradiation results in about 80 atom \% of carbon content [38]. The metal content could be then increased by two sequential purification 
steps: 1) deposit bombardment with atomic oxygen 2) deposit bombardment with atomic hydrogen. In the first step the carbonaceous material was fully removed from the material and in the next step the metal oxide was reduced to the metal. Although this method was successfully applied to obtain a deposit with high metal purity, the total exposure time was rather long: $40 \mathrm{~h}$ for oxygen and $2 \mathrm{~h}$ for hydrogen. The efficiency of atomic hydrogen only for purification of $\mathrm{Cu}-\mathrm{C}$ material obtained by an ion-induced deposition process at room temperature was shown by Chiang et al. [36]. It led to 99 atom \% pure $\mathrm{Cu}$ films. $\mathrm{H}_{2} / \mathrm{Ar}$ microplasma-assisted FEBID increased the $\mathrm{Cu}$ content from 12 atom \% to 41 atom \% but also caused extended halo deposits [39]. $\mathrm{Ga}^{+}$ion beam deposition showed that heating the substrate surface has a crucial influence on the properties of the deposit structure, from small isolated nanocrystals of $\mathrm{Cu}(\mathrm{ca} .20 \mathrm{~nm})$ at $25^{\circ} \mathrm{C}$ towards continuous thin films of pure copper at $100^{\circ} \mathrm{C}$, using (hfac)CuVTMS [40].

In this paper we will show results obtained by SEM, TEM, and electrical resistance monitoring during post-growth annealing of $\mathrm{Cu}-\mathrm{C}$ FEBID material from $\mathrm{Cu}$ (II) and $\mathrm{Cu}(\mathrm{I})$ precursors with respect to nanostructural changes and conductivity showing the potential of fabricating pure copper nanodots, from the as-grown amorphous $\mathrm{Cu}-\mathrm{C}$ deposit. The thermal energy input favors the migration of $\mathrm{Cu}$ atoms to coalesce to pure $\mathrm{Cu}$ nanocrystals being dispersed inside and on top of the carbonaceous matrix.

\section{Experimental FEBID}

The experiments were performed using a Hitachi 3600 scanning electron microscope (SEM) with a tungsten filament. The precursors were filled into their reservoirs inside a glove box in argon or dry nitrogen atmosphere. The deposition process has been carried out at room temperature on two types of substrates: $\mathrm{Si}$ with a $200 \mathrm{~nm}$ top layer of $\mathrm{SiO}_{2}$ and copper TEM grids with holey carbon films. The beam energy was fixed to $25 \mathrm{keV}$.
In this study bis(hexafluoroacetylacetonato)copper(II) $\left[\mathrm{Cu}(\mathrm{hfac})_{2}, \mathrm{Cu}\left(\mathrm{HC}_{5} \mathrm{O}_{2} \mathrm{~F}_{6}\right)_{2}\right]$ was used as a precursor and compared to earlier experiments with the precursors vinyltrimethylsilane copper(I) hexafluoroacetylacetonate, [(hfac)CuVTMS, $\left.\left(\mathrm{C}_{6} \mathrm{H}_{12} \mathrm{Si}\right) \mathrm{Cu}\left(\mathrm{HC}_{5} \mathrm{O}_{2} \mathrm{~F}_{6}\right)\right]$, and dimethylbutene copper(I) hexafluoroacetylacetonate [(hfac)CuDMB, $\left.\left(\mathrm{C}_{5} \mathrm{H}_{12}\right) \mathrm{Cu}\left(\mathrm{HC}_{5} \mathrm{O}_{2} \mathrm{~F}_{6}\right)\right]$ [41].

The precursor flux was estimated to be about 10 monolayers per second for $\mathrm{Cu}(\mathrm{hfac})_{2}$. The exposure parameters for $\mathrm{Cu}(\mathrm{hfac})_{2}$ for $1 \mu \mathrm{m} \times 1 \mu \mathrm{m}$ square deposits were: dwell time of $1 \mu \mathrm{s}$, pixel distance of $0.4 \mathrm{~nm}$, and frame repetitions varying from 100 to 1000 with refreshment times of $0.625 \mathrm{~s}$. The beam current was $0.4 \mathrm{nA}$. This corresponds to doses of $0.25 \mathrm{nC} / \mu \mathrm{m}^{2}$ (100 repetitions) and $2.5 \mathrm{nC} / \mu \mathrm{m}^{2}$ (1000 repetitions). For the $15 \mu \mathrm{m}$ long lines we used $100 \mu$ s dwell time per pixel, $0.5 \mathrm{~nm}$ pixel distance, and 300 line repetitions with a refreshment time of $3 \mathrm{~s}$. The beam current was $1 \mathrm{nA}$, which corresponds to the dose of $9 \mathrm{nC} / \mu \mathrm{m}^{2}$ and exposure time of $900 \mathrm{~s}$. Tip deposits were obtained by the stationary dot exposure mode exposing a pixel for two minutes. Line and freestanding-rod deposits with (hfac)CuDMB and (hfac)CuVTMS from earlier FEBID experiments $[39,40]$ were performed with a single scan at around $30 \mathrm{~nm} / \mathrm{s}$ with $600 \mathrm{pA}$.

\section{Annealing}

Post-growth annealing in vacuum was achieved by various setups shown in Figure 1. The conventional heating using a hot plate was performed without breaking the vacuum after the deposition process. The experiments were performed inside the SEM for a temperature range from room temperature up to $220^{\circ} \mathrm{C}$. The sample was supported in a custom-made massive copper block on a resistive heater (Boraelectric). The control of temperature was done with a thermocouple directly coupled to the base of the substrate. During the heating we observed an increase of the pressure inside the SEM chamber from $5 \times 10^{-6}$ to $5 \times 10^{-5}$ mbar. We cannot exclude possible reactions of the deposits with the residual gas (most likely water and residual

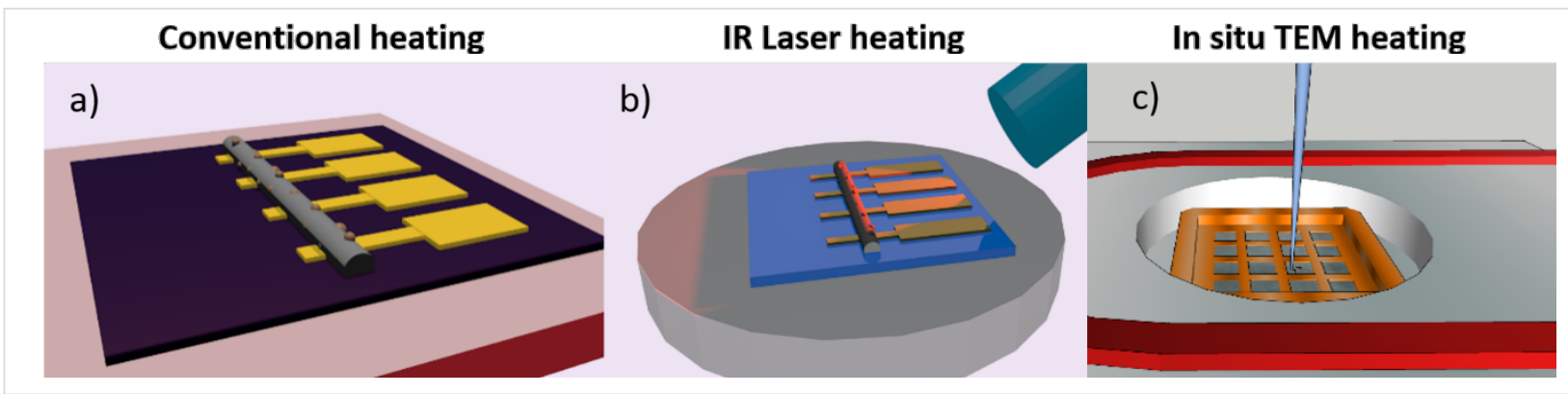

Figure 1: Sketch of post-growth annealing experiments: a) conventional heating using a hot plate in an SEM, b) SEM integrated laser heating; the substrate is heated by the IR laser pulses, c) post-growth thermal annealing during in situ TEM analysis. Conventional and IR laser annealing experiments were combined with in situ four-point probe resistance measurements. 
hydrocarbons) but we judge the influence as negligible as TEM annealing experiments at pressures better than $1 \times 10^{-6}$ mbar also resulted in nanocrystal formation (see below in Figure 6).

An infrared laser system was integrated into the SEM chamber for in situ post-growth annealing directly after the deposition. The system was composed of a SvetWheel's MU40-960-01 laser diode module and a fast diode current modulator VFM 20-25s (Messtec Power Converter $\mathrm{GmbH}$ ) triggered by a signal function generator. The wavelength of emitted photons was equal to $960 \mathrm{~nm}$ (corresponding to an energy of $1.29 \mathrm{eV}$ ) with a total maximum laser power of $29 \mathrm{~W}$. The tip of the laser optical fiber was placed in close vicinity of the FEBID deposit. The laser power, pulse duration and its frequency were adjustable by the signal generator. The size of the laser spot on the substrate was estimated to $65 \mu \mathrm{m} \times 130 \mu \mathrm{m}$, based on the molten area in $\mathrm{SiO}_{2}$ using the maximum laser power and a high pulse frequency.

The substrate surface temperatures generated by the laser during post-deposition annealing were determined experimentally and theoretically. Numerical finite element simulations with the annealing conditions (peak laser power of $13.6 \mathrm{~W}$, pulse duration of $10 \mu \mathrm{s}$ and frequency of $10 \mathrm{kHz}$ ) gave a stationary substrate surface temperature at the center of the laser beam of $158{ }^{\circ} \mathrm{C}$ which was reached after approximately $30 \mathrm{~s}$. This was in good agreement with the value of $150{ }^{\circ} \mathrm{C}$ deduced from in situ four-point-probe resistance measurements of a gold wire deposited by e-beam lithography and PVD metal lift-off together with the pre-structure of the four-point electrodes.

TEM in situ annealing of FEBID deposits from $\mathrm{Cu}(\mathrm{hfac})_{2}$ was performed with a Gatan double tilt heating holder (Model 652) in a JEOL-2200FS microscope. The samples were heated up to $220{ }^{\circ} \mathrm{C}$ with a ramp rate of $20 \mathrm{~K} / \mathrm{min}$.

\section{Characterization}

For SEM observation we used a Hitachi S4800 electron microscope and for the EDX measurements a Brooker/Oxford device mounted on a TESCAN LYRA microscope. EDX measurements were performed at $5 \mathrm{kV}$ and $2 \mathrm{nA}$ over $30 \mathrm{~s}$ with a $300 \mathrm{~nm} \times 300 \mathrm{~nm}$ scan area on the squares to account for in homogeneities in the lateral copper nanocrystal precipitation. Standard EDX software was used to calculate the composition from the spectra.

High-resolution TEM (HR-TEM) images were taken at $200 \mathrm{keV}$. Selected area diffraction (SAD) was taken using the second smallest selected area aperture corresponding to an area of $400 \mathrm{~nm}$ in diameter on the sample. Chemical mapping was obtained using electron energy loss spectroscopy (EELS) operated in the scanning TEM (STEM) mode. The $\mathrm{Cu} \mathrm{K}$ edge $(928 \mathrm{eV})$ and a signal energy window of $40 \mathrm{eV}(920-960 \mathrm{eV})$ after background subtraction were used to map the composition distribution of $\mathrm{Cu}$, see Figure S1 in Supporting Information File 1.

The changes of resistance during the annealing were monitored by four-point probe measurements using an SEM-integrated 15 -stage nanomanipulator from SmarAct. Conductive microprobes were connected via an SEM feedthrough to a Keithley 2400 Sourcemeter, with a source current of $100 \mu \mathrm{A}$ and a voltage compliance level of $500 \mathrm{mV}$.

\section{Results and Discussion As-deposited material}

Energy dispersive X-ray (EDX) analysis showed that at room temperature deposited $\mathrm{Cu}-\mathrm{C}$ lines and squares obtained from $\mathrm{Cu}(\mathrm{II})(\mathrm{hfac})_{2}$ had an atomic ratio of approximately $\mathrm{Cu} / \mathrm{C} / \mathrm{O} / \mathrm{F}=10: 64: 25: 1$ with standard deviations of \pm 1 atom $\%$ for $\mathrm{Cu}, \pm 2$ atom $\%$ for $\mathrm{C}, \pm 1$ atom $\%$ for $\mathrm{O}$, and \pm 0.3 atom $\%$ for $\mathrm{F}$ on eight deposits. This amounts to $10 \pm 2$ atom $\%$ of $\mathrm{Cu}$. With respect to the stoichiometric copper content in the $\mathrm{Cu}(\mathrm{hfac})_{2}$ precursor of 3.7 atom \% (disregarding the hydrogen) this was 2.7 times more copper in the deposit. The $\mathrm{Cu}$ content in deposits obtained from the (hfac)Cu(I)VTMS and (hfac)Cu(I)DMB precursors was about twice as high [41].

Transmission electron microscopy (TEM) showed that dot, square, and line deposits from $\mathrm{Cu}(\mathrm{II})(\mathrm{hfac})_{2}$ on an amorphous carbon membrane were amorphous (Figure 2).

In contrast, as-deposited freestanding rods from earlier FEBID experiments with (hfac)Cu(I)VTMS showed small $\mathrm{Cu}$ nanocrystals homogeneously dispersed in a polymeric carbonaceous matrix (see below in Figure 7 taken with a Philips EM-430 TEM at $300 \mathrm{keV}$ ). This matrix contains all the ligand elements: carbon, oxygen, fluorine, and silicon as well as probably some hydrogen (not detectable by EDX) [42]. The difference between amorphous and nano-composite materials obtained for the $\mathrm{Cu}(\mathrm{II})(\mathrm{hfac})_{2}$ and (hfac) $\mathrm{Cu}(\mathrm{I})$ VTMS precursor, respectively, can be attributed to the lower thermal stability of (hfac)CuVTMS which is $63{ }^{\circ} \mathrm{C}$ compared to $250{ }^{\circ} \mathrm{C}$ for $\mathrm{Cu}(\mathrm{hfac})_{2}$.

Electrical measurements showed that the as-deposited FEBID lines from $\mathrm{Cu}(\mathrm{hfac})_{2}$ were highly resistive with a value of a few gigaohms being around the measurement limit of the Keithley device. This is in line with our former experiments which showed for all three copper precursors nonconductive behavior for the room temperature as-deposited material [41]. 

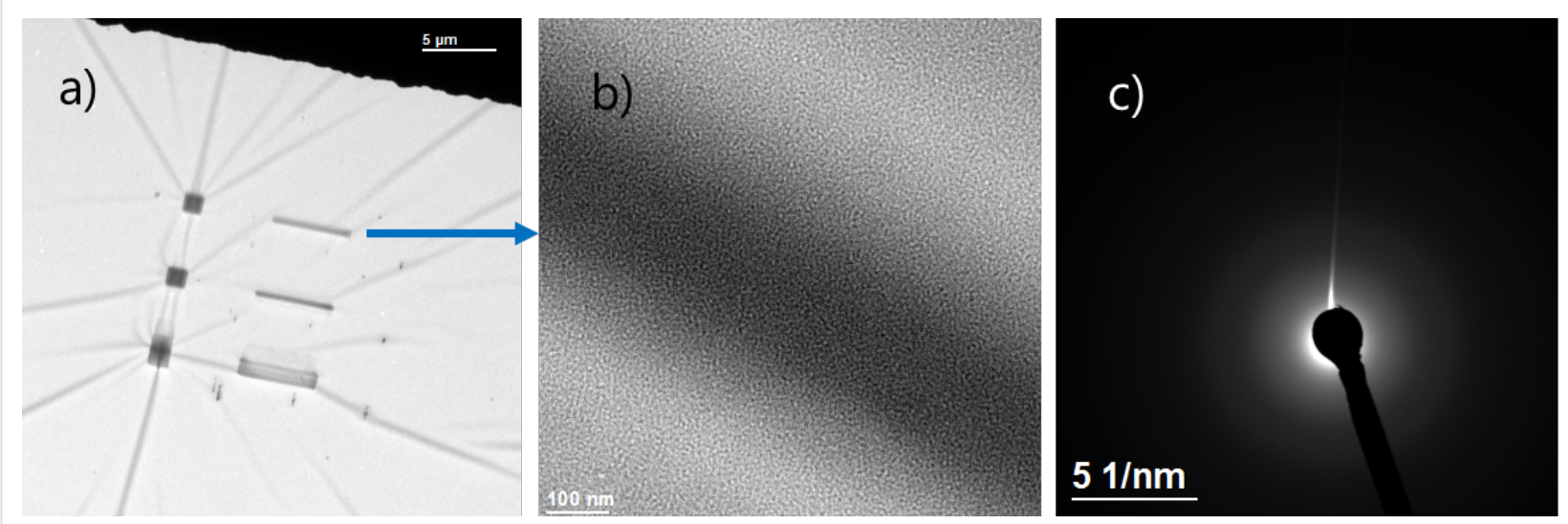

Figure 2: TEM of as-deposited lines and squares from $\mathrm{Cu}(\mathrm{hfac})_{2}$ on an amorphous carbon membrane on a TEM grid. a) An overview of deposits, b) zoom into a line deposit, c) a SAD pattern showing amorphous nature of the deposit.

\section{Annealed material SEM observations}

Upon annealing conventionally or with a laser the flat morphology of square, line, or tip deposits on the pre-patterned $\mathrm{SiO}_{2} / \mathrm{Si}$ substrate changes (Figure 3 and Figure 4). While the laser allows for local heating, the conventional hotplate approach allows for more accurate temperature measurements. The visible onset of $\mathrm{Cu}$ nanocrystal precipitation on the deposit surface starts at around $150{ }^{\circ} \mathrm{C}$ for the $\mathrm{Cu}(\mathrm{hfac})_{2}$ deposits on the pre-patterned $\mathrm{SiO}_{2} / \mathrm{Si}$ substrate. Further heating to about $200{ }^{\circ} \mathrm{C}$ for $30 \mathrm{~min}$ did not visibly change the appearance of the $\mathrm{Cu}$ nanocrystal precipitation.

EDX analysis after conventional heating to $200{ }^{\circ} \mathrm{C}$ for $30 \mathrm{~min}$ showed an atomic ratio of approximately $\mathrm{Cu} / \mathrm{C} / \mathrm{O} / \mathrm{F}=12: 75: 13: 0$ with standard deviations of \pm 2 atom $\%$ for $\mathrm{Cu}, \pm 2$ atom $\%$ for $\mathrm{C}$, and \pm 1 atom $\%$ for $\mathrm{O}$ on the same deposits. The $12 \pm 2$ atom $\% \mathrm{Cu}$ content in the deposit is thus rather constant compared to the as-grown sample value of $10 \pm 2$ atom $\% \mathrm{Cu}$ within the error limits and may have even been slightly overestimated systematically by the standard EDX software due to the surface-precipitated $\mathrm{Cu}$ nanocrystals corrected for absorption. Compared to the as-deposited material the fluorine completely disappeared and the oxygen content was halved. An estimation of the amount of precipitated copper nanocrystals that are visible in SEM gave only about 9 to 17 wt \% (see Supporting Information File 1). Compared to the average $\mathrm{Cu}$ content in the as-grown and deposited samples of roughly 11 atom \% (corresponding to an average $37 \mathrm{wt} \% \mathrm{Cu}$ ) this means that 20 to $28 \mathrm{wt} \%$ or 5 to 7 atom \% of the copper dispersed in the matrix did not precipitate to be visible in SEM or segregated during the annealing. The matrix deposit volume shrunk during annealing to about $70 \%$ of its initial volume pointing to reticulation of the carbon network after release of fluorine and oxygen.
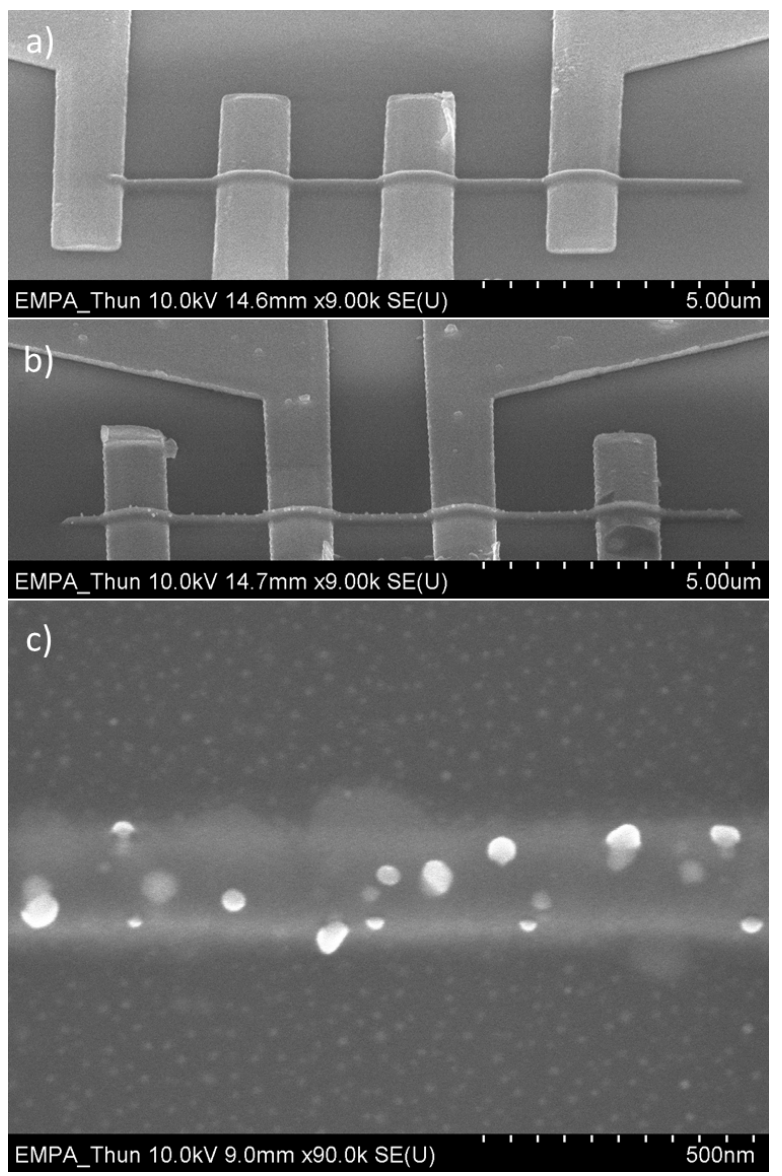

Figure 3: Post-growth annealing of FEBID line from $\mathrm{Cu}(\mathrm{hfac})_{2}$ between four gold electrodes. SEM tilt images $\left(60^{\circ}\right)$ of a) as-deposited line, b) after annealing at $200{ }^{\circ} \mathrm{C}$ for $30 \mathrm{~min}$, and c) top-view zoom into central part of the annealed line showing the Cu nanocrystals on the line deposit and inside as well as on the halo deposit.

Interestingly, the size of the nanocrystals is much smaller in the thin halo region of the deposited line, yet the nanocrystal density is much larger. This may be due to the small amount of 

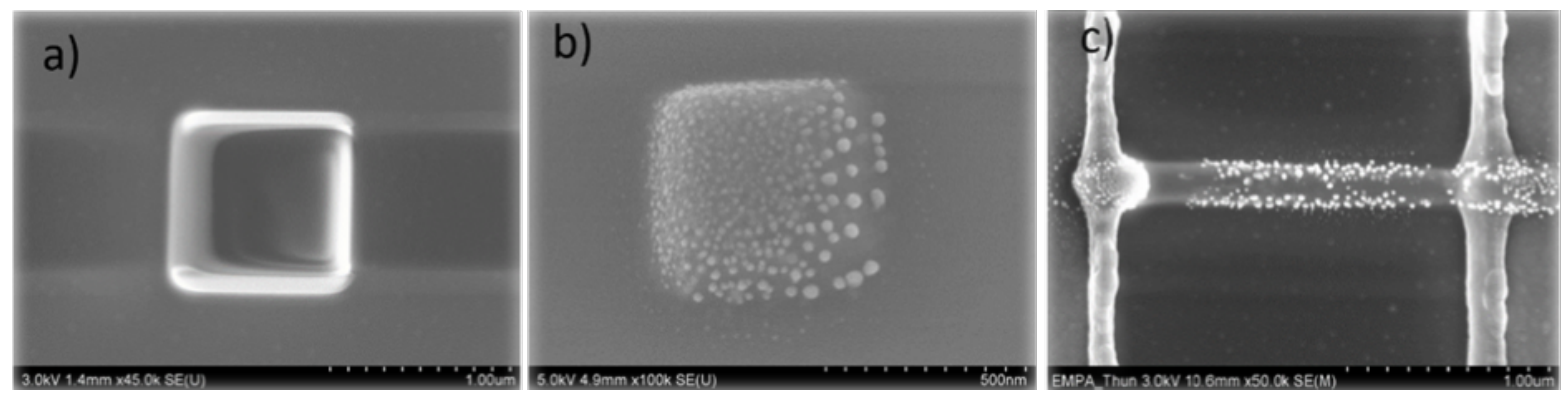

Figure 4: Post-growth laser annealing of FEBID deposits from $\mathrm{Cu}(\mathrm{hfac})_{2}$. SEM top view images of a) as-deposited square, b) Cu nanocrystals forming due to laser annealing at a power of $13.6 \mathrm{~W}$ over $1 \mathrm{~min}, \mathrm{c}$ ) laser-annealed FEBID line between two gold electrodes.

deposit material available to form the $\mathrm{Cu}$ nanocrystals but could be also due to the low irradiation dose of these regions and hence a slightly less reticulated carbon network which facilitates segregation at many places.

For laser-induced heating we found the same phenomenon of surface precipitation of $\mathrm{Cu}$ nanocrystals although the annealing time was only one minute. Also the same trend in the variation of the atomic ratio with annealing was found. Energy dispersive X-ray measurements of the deposit shown in Figure $4 \mathrm{a}$ and Figure 4bgave an atomic ratio of $\mathrm{Cu} / \mathrm{C} / \mathrm{O} / \mathrm{F}=$ 9:52:32:6 for the as-grown FEBID material which changed to $\mathrm{Cu} / \mathrm{C} / \mathrm{O} / \mathrm{F}=10: 66: 23: 0.6$ after laser annealing. Considering the error limits of 2 atom \% there is no fundamental difference to the trends and absolute values for $\mathrm{Cu}$ stated for conventional annealing. The $\mathrm{Cu} / \mathrm{C}=1: 6.6$ ratio after laser annealing of $1 \mathrm{~min}$ at around $158{ }^{\circ} \mathrm{C}$ (see section Experimental) is smaller than for thermal annealing, however, time and annealing temperature were lower for the laser than for thermal annealing. Figure $4 \mathrm{c}$ shows that precipitation of $\mathrm{Cu}$ nanocrystals is not fully uniform across the line length in contrast to the conventionally annealed lines in Figure $3 \mathrm{~b}$ and Figure 3c (see also Figure S5 in Supporting Information File 1). At the vicinity to the gold electrodes there are fewer nanocrystals visible which might be due to a varying distribution of the laser-induced temperature.
The precipitation of $\mathrm{Cu}$ nanocrystals on the initial deposit surface was observed also in former experiments with the $\mathrm{Cu}(\mathrm{I})$ precursors. Figure 5 shows SEM tilt views of a periodic three dimensional line deposit obtained from (hfac) $\mathrm{Cu}(\mathrm{DMB})$. Such periodicity can arise when the vertical deposition rate is comparable to the scan speed of the focused electron beam. For the annealing experiments this is not of importance (for more details we refer to Bret et al. [43]). Upon annealing the same precipitation at deposit surfaces and at halo regions due to forward and backscattered electrons can be seen (Figure 5a-c). For a tip deposit the same features develop upon heating pointing to the fact that the dwell time per pixel during FEBID is not a very sensitive parameter for $\mathrm{Cu}$ nanocrystal precipitation (Figure 5d). The prolonged irradiation of a few minutes in the spot mode during FEBID with $20 \mathrm{keV}$ electrons does not seem to change the reticulation of the matrix in such a way that formation of $\mathrm{Cu}$ nanocrystals remains contained inside the matrix. On the other hand, post-irradiation experiments with electrons energy of $5 \mathrm{keV}$ were shown to be already effective to change the electron transport mechanisms in $\mathrm{Pt}-\mathrm{C}$ and $\mathrm{W}-\mathrm{C}$ FEBID deposits [27-29].

\section{TEM observations}

In Figure 6, the results of in situ TEM annealing experiments performed on the line and square deposit material from
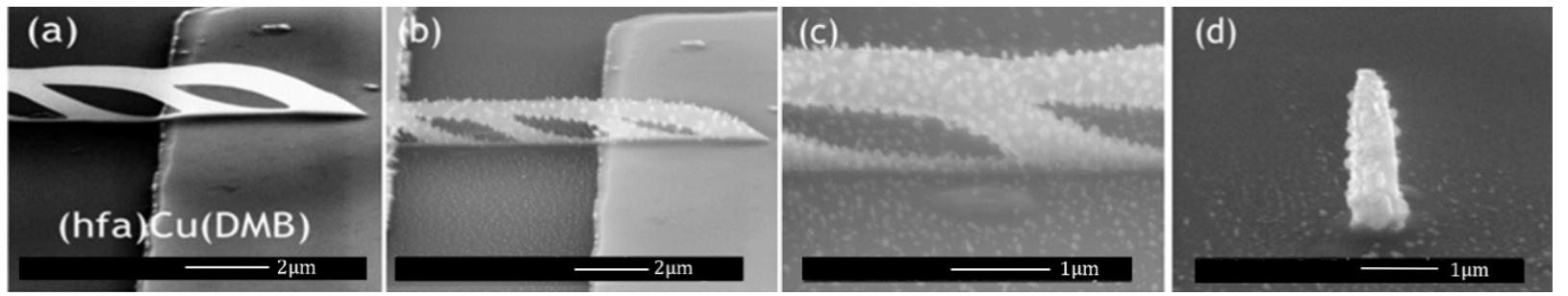

Figure 5: Periodic 3D FEBID line deposits from (hfac) $\mathrm{Cu}\left(\mathrm{DMB}\right.$ ) between gold electrodes on $\mathrm{SiO}_{2} / \mathrm{Si}$. SEM tilt images: a) before annealing, b) after in situ vacuum annealing, c) zoom on Cu nanocrystals, d) tip deposit showing also Cu nanocrystal formation. 
$\mathrm{Cu}(\mathrm{hfac})_{2}$ FEBID (shown in Figure 2) are presented. During annealing the deposits were not observed except for one to capture the temperature of crystal formation in a video.

The formation of nanocrystals took place at a temperature of $200{ }^{\circ} \mathrm{C}$. The time for $\mathrm{Cu}$ nanocrystal formation was below $500 \mathrm{~ms}$ - the time range of the CCD camera to take a video frame image. After this rapid transition the nanocrystal arrangement did not change anymore. We compared it to regions that were not observed in TEM and found no differences so that the given temperature for crystal formation was not subject to irradiation during the video. We have tried different annealing rates and taken TEM images at different beam currents (which can be easily done by spreading the electron beam) and the results remained the same. In Figure 6 it can be seen that the amorphous material from $\mathrm{Cu}(\mathrm{hfac})_{2}$ turns to nano-composite with $\mathrm{Cu}$ nanocrystals embedded in an amorphous carbonaceous matrix. The size ranges from $2 \mathrm{~nm}$ to $20 \mathrm{~nm}$ for the face centered cubic (fcc) copper nanocrystals. This underlines that post-growth annealing has the potential to achieve one-digitnanometer sized copper nanocrystals when using a high-resolution electron microscope for smallest dot deposition [44].

Theoretically, annealing a hemispherical FEBID deposit having a radius $r_{\text {met }}$ and containing a given weight percentage $w_{\text {met }}$ to pure metal would result in a metal hemisphere of radius

$$
r_{\mathrm{met}}=r_{\mathrm{dep}} \cdot \sqrt[3]{w_{\mathrm{met}} \frac{\rho_{\mathrm{dep}}}{\rho_{\mathrm{met}}}}
$$

with $\rho_{\text {met }}$ and $\rho_{\text {dep }}$ being the densities of the metal and deposit, respectively. For our deposits from $\mathrm{Cu}(\mathrm{hfac})_{2}$ Equation 1 yields $r_{\text {met }}=0.46 \cdot r_{\text {dep }}$ with $w_{\text {met }}=0.35$ (corresponding to the 10 atom $\% \mathrm{Cu}$ in the as-grown deposit, see section "As-deposited material"), $\rho_{\text {dep }}=2.5 \mathrm{~g} / \mathrm{cm}^{3}$ (from [45]) and $\rho_{\mathrm{Cu}}=8.9 \mathrm{~g} / \mathrm{cm}^{3}$. This means that $1 \mathrm{~nm} \mathrm{Cu}$ dots could be annealed out of a $2 \mathrm{~nm}$ sized hemispherical FEBID material from $\mathrm{Cu}(\mathrm{hfac})_{2}$.

Selected results of earlier in situ TEM annealing experiments within a Philips EM-430 TEM on freestanding FEBID rods obtained from (hfac)Cu(VTMS) are shown in Fsigure 7. Interestingly, the comparison of Figure $7 \mathrm{~b}$ and Figure $7 \mathrm{c}$ shows that the place of $\mathrm{Cu}$ nanocrystal precipitation can be controlled by post-irradiation with the high-energy electrons of a TEM in contrast to the experiments with $\mathrm{Cu}(\mathrm{hfac})_{2}$. The $\mathrm{Cu}$ crystals segregate around $140{ }^{\circ} \mathrm{C}$ inside the carbonaceous matrix when the deposit was exposed to the $300 \mathrm{keV}$ electrons of the TEM during the annealing experiment, probably due to an electrontriggered reticulation of the polymeric carbonaceous matrix. The stronger reticulation of the carbon matrix seems to suppress the long-range mobility of $\mathrm{Cu}$ atoms to diffuse to the outside surface. In contrast, irradiation with only $20 \mathrm{keV}$ is not efficient in reticulating the matrix in such a way that out-diffusion is hampered as was observed for (hfac)CuDMB deposits in Figure 5 and for $\mathrm{Cu}(\mathrm{hfac})_{2}$ deposits in Figure 3 and Figure 4.

In contrast, purification by electron beam induced heating of freestanding rods obtained from FEBID with (hfac)CuVTMS [42] gave much larger pure copper crystals (up to $150 \mathrm{~nm}$ in size). In comparison to the above results the differences may be explained by invoking an electron stimulated desorption effect which was suggested for FEBID by van Dorp et al. [46] which would facilitate the desorption of carbonaceous fragments and thus the formation of larger copper nanocrystals.

\section{Electrical measurements}

Figure 8 shows the typical behavior of a $\mathrm{Cu}-\mathrm{C}$ FEBID line for a heating/cooling cycle. The as-deposited lines were non-conduc-
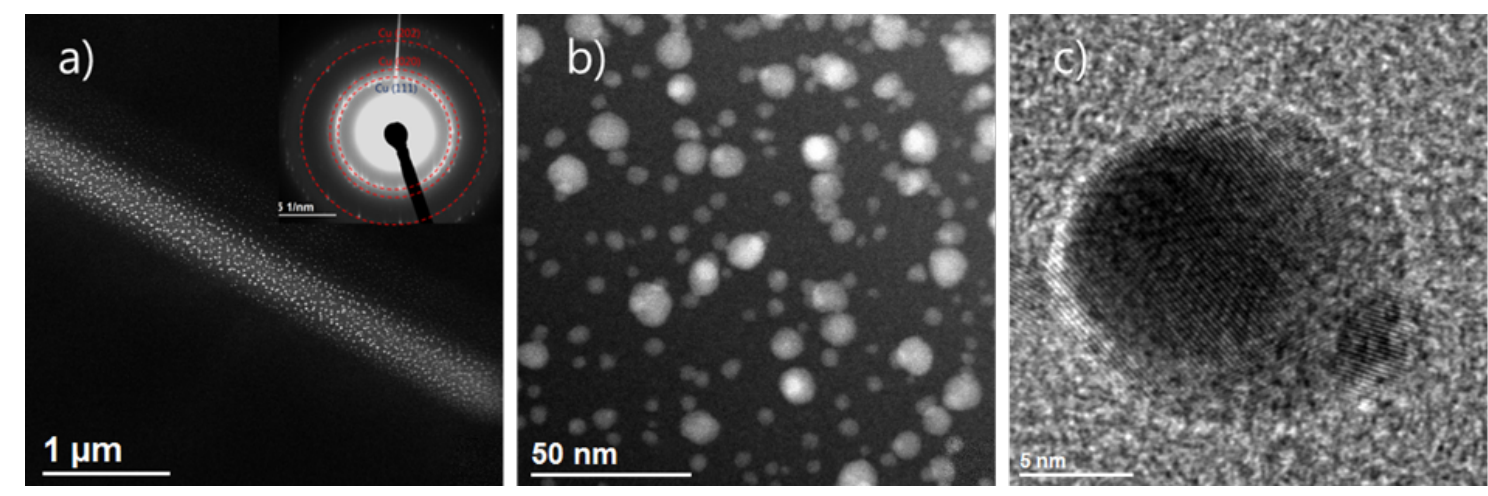

Figure 6: In situ TEM annealing for $10 \mathrm{~min}$ at $220^{\circ} \mathrm{C}$ on a line deposit from $\mathrm{Cu}(\mathrm{hfac})_{2}$ shown in Figure 2. a) STEM high angle annular dark field (STEM-HAADF) image of Cu nanocrystals forming from the deposit material. b) HAADF image showing distribution of Cu nanocrystals. c) High-resolution TEM (HR-TEM) image of $15 \mathrm{~nm}$ sized polycrystalline Cu precipitate. The inset shows the SAD pattern of Cu fcc nanocrystals. 


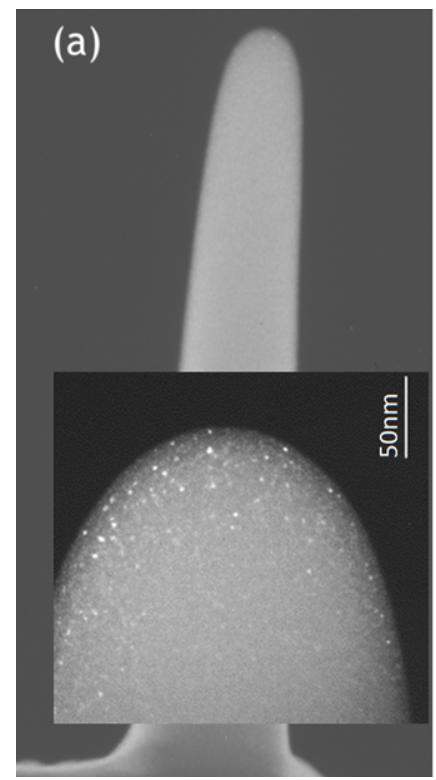

(b)

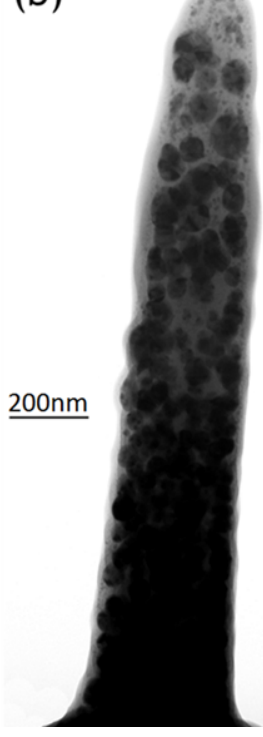

(C)

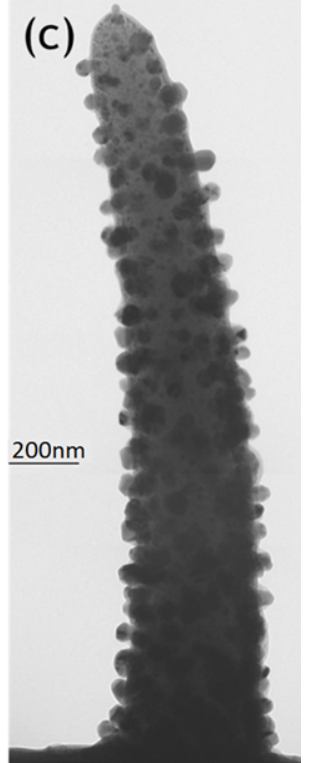

Figure 7: TEM in situ annealing of FEBID rods grown from (hfac)Cu(VTMS). a) Dark field image of an as-deposited freestanding rod. Inset: rod apex with small $\mathrm{Cu}$ nanocrystals in carbonaceous matrix. b) Bright-field image of same rod after $270{ }^{\circ} \mathrm{C}$ annealing and continuous TEM observation $(200 \mathrm{keV})$. Large Cu nanocrystals form inside the rod. c) Bright field image of another rod not observed during the same annealing process. Cu nanocrystals form at the outside surface of the rod.

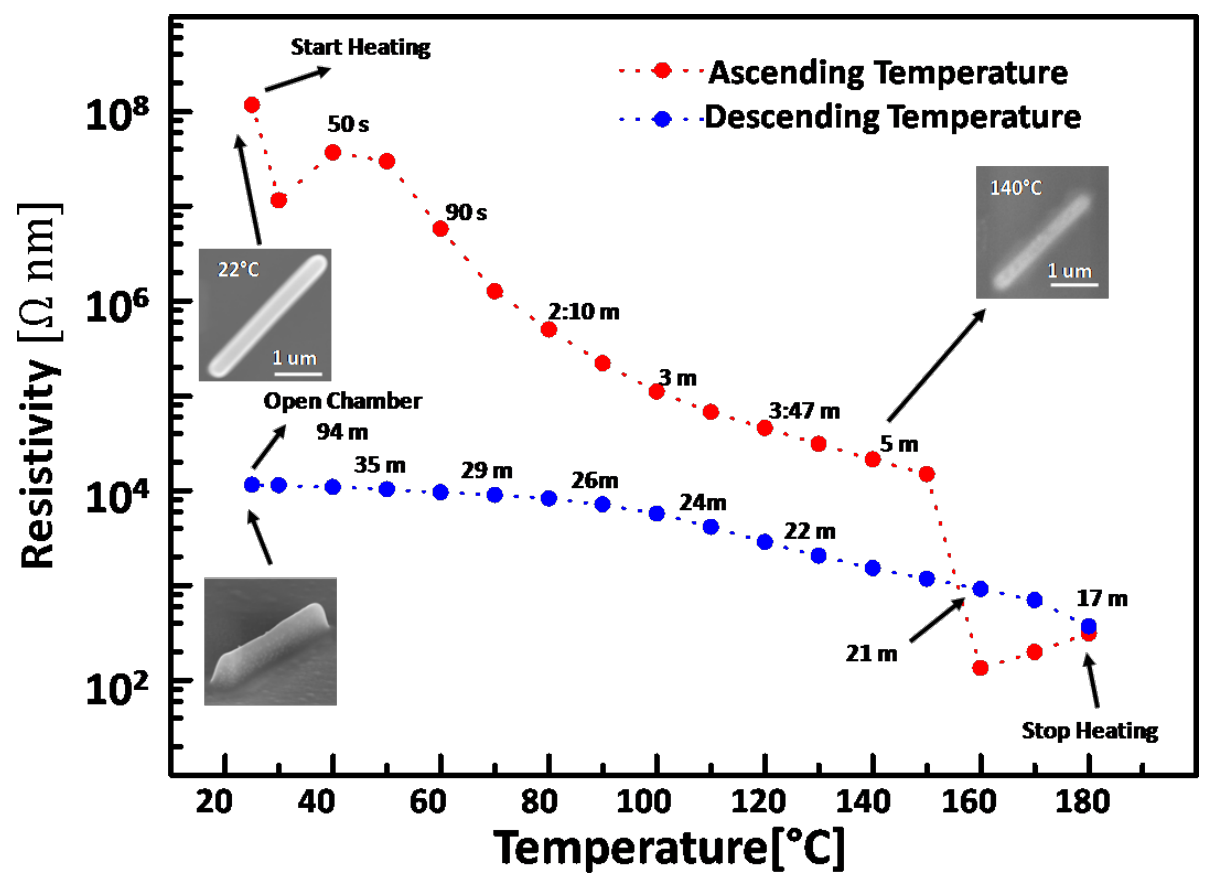

Figure 8: Calculated resistivity from the resistance measurement of a $\mathrm{Cu}-\mathrm{C}$ line during in situ post-growth heating with a hot plate (red dots) and cooling down (blue dots) inside the SEM chamber. The resistance did not change when opening the chamber. The top SEM images show the morphology changes of an adjacent FEBID line which was observed simultaneously during the in situ resistance measurement.

tive, showing an electrical resistance of few gigaohms at room temperature. After thermal annealing the resistance dropped by four to five orders of magnitude to hundreds of kiloohms. At the current densities, used in the experiments (less than $0.1 \mathrm{MA} / \mathrm{cm}^{2}$ ) the migration process of $\mathrm{Cu}$ atoms is rather slow. Gazzadi and Frabboni [47] reported grain formation and 
electromigration in $\mathrm{Pt}-\mathrm{C}$ material at current densities approaching $10 \mathrm{MA} / \mathrm{cm}^{2}$ which is about a factor 100 below our maximum current densities applied. A large resistance drop was observed after nanocrystals precipitated on the surface around $150{ }^{\circ} \mathrm{C}$.

An increase in resistivity of one order of magnitude can be observed upon the cooling cycle from $180{ }^{\circ} \mathrm{C}$ to $25{ }^{\circ} \mathrm{C}$. The temperature coefficient for bulk $\mathrm{Cu}$ is $0.00386 \mathrm{~K}^{-1}$ and would amount to an increase of the resistance by a factor of 1.6 only for the temperature difference of $155 \mathrm{~K}$. The thermally activated transport observed in this case, can be due to the variable range hopping mechanism [48], corresponding to the insulating transport regime for granular materials, as it was observed previously for various FEBID deposits, composed of metallic grains embedded in carbonaceous matrix [49]. More detailed studies are planned to characterize the electronic transport of this material including the question whether the resistance-vstemperature behavior of the samples would be stable. Here we focused on a proof of concept study.

\section{Conclusion}

We have shown that nanostructural changes were induced in $\mathrm{Cu}-\mathrm{C}$ FEBID material from $\mathrm{Cu}(\mathrm{I})$ and $\mathrm{Cu}(\mathrm{II})$ precursors upon post-growth annealing causing the segregation and precipitation of $\mathrm{Cu}$ nanocrystals. No fundamental differences between laser induced heating and conventional heating in the SEM and TEM with respect to trends and composition values were observed. As deposited the $\mathrm{Cu}-\mathrm{C}$ FEBID deposits obtained from $\mathrm{Cu}$ (hfac $)_{2}$ were amorphous while nanocomposite deposits were obtained from (hfac)CuVTMS and (hfac)CuDMB. The as-deposited materials were non-conductive. The transition into conductive material as well as the segregation and precipitation of the copper atoms occur upon conventional or laser heating. The surface precipitation of copper nanocrystals upon annealing opens a route for depositing pure $\mathrm{Cu}$ nanodot patterns using highly focused electron beams.

\section{Supporting Information}

Supporting Information features additional information about the chemical mapping with electron energy loss spectroscopy, the estimation of $\mathrm{Cu}$ precipitation on deposit, and the distribution of $\mathrm{Cu}$ nanocrystals along the $\mathrm{Cu}-\mathrm{C}$ lines after conventional and IR laser thermal annealing.

\section{Supporting Information File 1}

Additional experimental data.

[http://www.beilstein-journals.org/bjnano/content/ supplementary/2190-4286-6-156-S1.pdf]

\section{Acknowledgements}

Metal deposition for gold electrode lift-off by Vipin Chawla is acknowledged. I.U. would like to thank Philippe Buffat for the TEM heating experiments at CIME at EPFL shown in Figure 7. A.S and I.U acknowledge support by the COST Action CM1301 (CELINA). A.R.V. acknowledges the support of the program 'Ciência sem Fronteiras' from CNPq(Brazil) and State University of Campinas (UNICAMP).

\section{References}

1. Utke, I.; Gölzhäuser, A. Angew. Chem., Int. Ed. 2010, 49, 9328-9330. doi:10.1002/anie.201002677

2. Utke, I.; Hoffmann, P.; Melngailis, J. J. Vac. Sci. Technol., B 2008, 26, 1197. doi:10.1116/1.2955728

3. Kolb, F.; Schmoltner, K.; Huth, M.; Hohenau, A.; Krenn, J.; Klug, A.; List, E. J. W.; Plank, H. Nanotechnology 2013, 24, 305501. doi:10.1088/0957-4484/24/30/305501

4. Huth, M.; Kolb, F.; Plank, H. Appl. Phys. A 2014, 117, 1689-1696. doi:10.1007/s00339-014-8631-9

5. Gabureac, M.; Bernau, L.; Utke, I.; Boero, G. Nanotechnology 2010, 21, 115503. doi:10.1088/0957-4484/21/11/115503

6. Gabureac, M. S.; Bernau, L.; Boero, G.; Utke, I. IEEE Trans. Nanotechnol. 2013, 12, 668-673. doi:10.1109/TNANO.2013.2266733

7. Schwalb, C. H.; Grimm, C.; Baranowski, M.; Sachser, R.; Porrati, F.; Reith, H.; Das, P.; Müller, J.; Völklein, F.; Kaya, A.; Huth, M. Sensors 2010, 10, 9847-9856. doi:10.3390/s101109847

8. Edinger, K.; Gotszalk, T.; Rangelow, I. W. J. Vac. Sci. Technol., B 2001, 19, 2856. doi:10.1116/1.1420580

9. Makise, K.; Mitsuishi, K.; Shimojo, M.; Furuya, K. Nanotechnology 2009, 20, 425305. doi:10.1088/0957-4484/20/42/425305

10. Utke, I.; Jenke, M. G.; Röling, C.; Thiesen, P. H.; lakovlev, V.; Sirbu, A.; Mereuta, A.; Caliman, A.; Kapon, E. Nanoscale 2011, 3, 2718. doi:10.1039/C1NR10047E

11. Gavagnin, M.; Wanzenboeck, H. D.; Belić, D.; Bertagnolli, E. ACS Nano 2013, 7, 777-784. doi:10.1021/nn305079a

12. Fernández-Pacheco, A.; De Teresa, J. M.; Szkudlarek, A.; Córdoba, R.; Ibarra, M. R.; Petit, D.; O’Brien, L.; Zeng, H. T.; Lewis, E. R.; Read, D. E.; Cowburn, R. P. Nanotechnology 2009, 20, 475704. doi:10.1088/0957-4484/20/47/475704

13. Winhold, M.; Weirich, P. M.; Schwalb, C. H.; Huth, M. Appl. Phys. Lett. 2014, 105, 162603. doi:10.1063/1.4898819

14. Höflich, K.; Becker, M.; Leuchs, G.; Christiansen, S. Nanotechnology 2012, 23, 185303. doi:10.1088/0957-4484/23/18/185303

15. Brintlinger, T.; Fuhrer, M. S.; Melngailis, J.; Utke, I.; Bret, T.; Perentes, A.; Hoffmann, P.; Abourida, M.; Doppelt, P. J. Vac. Sci. Technol., B 2005, 23, 3174. doi:10.1116/1.2130355

16. Kim, S.; Kulkarni, D. D.; Rykaczewski, K.; Henry, M.; Tsukruk, V. V.; Fedorov, A. G. IEEE Trans. Nanotechnol. 2012, 11, 1223-1230. doi:10.1109/TNANO.2012.2220377

17. Utke, I.; Hoffmann, P.; Berger, R.; Scandella, L. Appl. Phys. Lett. 2002, 80, 4792. doi:10.1063/1.1489097

18. Belova, L. M.; Hellwig, O.; Dobisz, E.; Dan Dahlberg, E. Rev. Sci. Instrum. 2012, 83, 093711. doi:10.1063/1.4752225

19. Fernández-Pacheco, A.; Serrano-Ramón, L.; Michalik, J. M.; Ibarra, M. R.; De Teresa, J. M.; O’Brien, L.; Petit, D.; Lee, J.; Cowburn, R. P. Sci. Rep. 2013, 3, No. 1492. doi:10.1038/srep01492 
20. Szkudlarek, A.; Szmyt, W.; Kapusta, C.; Utke, I. Appl. Phys. A 2014, 117, 1715-1726. doi:10.1007/s00339-014-8751-2

21. Winkler, R.; Szkudlarek, A.; Fowlkes, J. D.; Rack, P. D.; Utke, I.; Plank, H. ACS Appl. Mater. Interfaces 2015, 7, 3289-3297. doi:10.1021/am508052k

22. Sachser, R.; Reith, H.; Huzel, D.; Winhold, M.; Huth, M. ACS Appl. Mater. Interfaces 2014, 6, 15868-15874. doi:10.1021/am503407y

23. Stanford, M. G.; Lewis, B. B.; Noh, J. H.; Fowlkes, J. D.; Roberts, N. A.; Plank, H.; Rack, P. D. ACS Appl. Mater. Interfaces 2014, 6, 21256-21263. doi:10.1021/am506246z

24. Plank, H.; Noh, J. H.; Fowlkes, J. D.; Lester, K.; Lewis, B. B.; Rack, P. D. ACS Appl. Mater. Interfaces 2014, 6, 1018-1024. doi:10.1021/am4045458

25. Geier, B.; Gspan, C.; Winkler, R.; Schmied, R.; Fowlkes, J. D.; Fitzek, H.; Rauch, S.; Rattenberger, J.; Rack, P. D.; Plank, H. J. Phys. Chem. C 2014, 118, 14009-14016. doi:10.1021/jp503442b

26. Begun, E.; Dobrovolskiy, O. V.; Kompaniiets, M.; Sachser, R.; Gspan, C.; Plank, H.; Huth, M. Nanotechnology 2015, 26, 075301. doi:10.1088/0957-4484/26/7/075301

27. Plank, H.; Kothleitner, G.; Hofer, F.; Michelitsch, S. G.; Gspan, C.; Hohenau, A.; Krenn, J. J. Vac. Sci. Technol., B 2011, 29, 051801. doi:10.1116/1.3622314

28. Plank, H.; Haber, T.; Gspan, C.; Kothleitner, G.; Hofer, F. Nanotechnology 2013, 24, 175305. doi:10.1088/0957-4484/24/17/175305

29. Weirich, P. M.; Winhold, M.; Schwalb, C. H.; Huth, M. Beilstein J. Nanotechnol. 2013, 4, 919-926. doi:10.3762/bjnano.4.103

30. Botman, A.; Mulders, J. J. L.; Hagen, C. W. Nanotechnology 2009, 20, 372001. doi:10.1088/0957-4484/20/37/372001

31. Mulders, J. J. L.; Belova, L. M.; Riazanova, A. Nanotechnology 2011, 22, 055302. doi:10.1088/0957-4484/22/5/055302

32. Roberts, N. A.; Magel, G. A.; Hartfield, C. D.; Moore, T. M.; Fowlkes, J. D.; Rack, P. D. J. Vac. Sci. Technol., A 2012, 30, 041404. doi:10.1116/1.4731254

33. Roberts, N. A.; Gonzalez, C. M.; Fowlkes, J. D.; Rack, P. D. Nanotechnology 2013, 24, 415301. doi:10.1088/0957-4484/24/41/415301

34. Roberts, N. A.; Fowlkes, J. D.; Magel, G. A.; Rack, P. D. Nanoscale 2013, 5, 408. doi:10.1039/c2nr33014h

35. Temple, D.; Reisman, A. J. Electrochem. Soc. 1989, 136, 3525. doi:10.1149/1.2096498

36. Chiang, T. P.; Sawin, H. H.; Thompson, C. V. J. Vac. Sci. Technol., A 1997, 15, 2677. doi:10.1116/1.580942

37. Lee, W. H.; Seo, B. S.; Byun, I. J.; Ko, Y. G.; Kim, J. Y.; Lee, J. G. J. Korean Phys. Soc. 2002, 33, 107-109.

38. Rosenberg, S. G.; Barclay, M.; Fairbrother, D. H. ACS Appl. Mater. Interfaces 2014, 6, 8590-8601. doi:10.1021/am501457h

39. Miyazoe, H.; Utke, I.; Kikuchi, H.; Kiriu, S.; Friedli, V.; Michler, J.; Terashima, K. J. Vac. Sci. Technol., B 2010, 28, 744. doi:10.1116/1.3449808

40. Della Ratta, A. D.; Melngailis, J.; Thompson, C. V. J. Vac. Sci. Technol., B 1993, 11, 2195. doi:10.1116/1.586455

41. Luisier, A.; Utke, I.; Bret, T.; Cicoira, F.; Hauert, R.; Rhee, S.-W.; Doppelt, P.; Hoffmann, P. J. Electrochem. Soc. 2004, 151, C590. doi:10.1149/1.1779335

42. Utke, I.; Luisier, A.; Hoffmann, P.; Laub, D.; Buffat, P. A. Appl. Phys. Lett. 2002, 81, 3245. doi:10.1063/1.1517180
43. Bret, T.; Utke, I.; Gaillard, C.; Hoffmann, P. J. Vac. Sci. Technol., B 2004, 22, 2504. doi:10.1116/1.1800356

44. Van Dorp, W. F.; van Someren, B.; Hagen, C. W.; Kruit, P.; Crozier, P. A. Nano Lett. 2005, 5, 1303-1307. doi:10.1021/nl050522i

45. Friedli, V.; Utke, I.; Mølhave, K.; Michler, J. Nanotechnology 2009, 20 , 385304. doi:10.1088/0957-4484/20/38/385304

46. Van Dorp, W. F.; Hansen, T. W.; Wagner, J. B.; De Hosson, J. T. M. Beilstein J. Nanotechnol. 2013, 4, 474-480. doi:10.3762/bjnano.4.56

47. Gazzadi, G. C.; Frabboni, C. Appl. Phys. Lett. 2009, 94, 173112. doi:10.1063/1.3119582

48. Beloborodov, I. S.; Lopatin, A. V.; Vinokur, V. M.; Efetov, K. B. Rev. Mod. Phys. 2007, 79, 469-518. doi:10.1103/RevModPhys.79.469

49. Huth, M.; Porrati, F.; Schwalb, C.; Winhold, M.; Sachser, R.; Dukic, M.; Adams, J.; Fantner, G. Beilstein J. Nanotechnol. 2012, 3, 597-619. doi:10.3762/bjnano.3.70

\section{License and Terms}

This is an Open Access article under the terms of the Creative Commons Attribution License (http://creativecommons.org/licenses/by/2.0), which permits unrestricted use, distribution, and reproduction in any medium, provided the original work is properly cited.

The license is subject to the Beilstein Journal of Nanotechnology terms and conditions: (http://www.beilstein-journals.org/bjnano)

The definitive version of this article is the electronic one which can be found at: doi:10.3762/bjnano.6.156 